\title{
Waste generation as a side impact of COVID-19 pandemic: Communication on correct disposal of single-use face masks
}

\author{
Débora Tomaszewski ${ }^{1}$
}

${ }^{1}$ Affiliation not available

April 12, 2021

\begin{abstract}
The rapid global spread of SARS-CoV-2 and the resulting Coronavirus disease (COVID-19) pandemic has led to urgent efforts to contain and mitigate transmission. The use of face masks became a primary measure to limit the spread, which increased the production and consequent waste generation. It is estimated that globally 129 billion single-use face masks are discharged into the environment every month. Besides to add to already great concerns over plastic pollution, contaminated face masks not properly handled also poses a health risk. The health and environmental consequences caused by the inadequate disposal of single-use face masks are treated in this study as an eminent risk to be properly communicated. This study framed the waste generation as a side impact of the COVID-19 pandemic and analysed how the communication has been made regarding the correct disposal of single-use masks, with focus in users of public transport in Stockholm region. National and regional authorities are recognized as the main responsibles for the communication about correct disposal, together with manufacturers and suppliers of single-use face masks. Disclosure and informative material of four government authorities and instruction manuals of eight brands of single-use face masks are analysed according to: i) presence / absence of information (about the disposal); ii) type of communication (visual or written); iii) message transmitted and; ix) availability in other languages. It was found guidance about correct disposal of face mask in two thirds of the existing communication, that is mainly written and with few visual aids. Half of communication is made only in Swedish and with no sufficient focus on the importance of correct disposal neither with reference to trash bins with lid. It suggests that the current communication about how to dispose single-use masks safely may not be enough, which is affecting the perception of risk by the population and worsening the health and environmental consequences caused by the inadequate disposal.
\end{abstract}

\section{Hosted file}

Milj\selectlanguage\{ngerman\}öriskkommunikation-final.pdf available at https://authorea.com/ users/407380/articles/517695-waste-generation-as-a-side-impact-of-covid-19-pandemiccommunication-on-correct-disposal-of-single-use-face-masks 